\title{
Designing a GA-Based Robust Controller For Load Frequency Control (LFC)
}

\author{
Koosha Soleimani \\ Electrical and Computer Engineering Department \\ Isfahan University of Technology \\ Isfahan, Iran
}

\author{
Jalil Mazloum \\ Electrical Engineering Department \\ Shahid Sattari Aeronautical University of Science and Technology \\ Tehran, Iran
}

\begin{abstract}
Power systems include multiple units linked together to produce constantly moving electric power flux. Stability is very important in power systems, so controller systems should be implemented in power plants to ensure power system stability either in normal conditions or after the events of unwanted inputs and disorder. Frequency and active power control are more important regarding stability. Our effort focused on designing and implementing robust PID and PI controllers based on genetic algorithm by changing the reference of generating units for faster damping of frequency oscillations. Implementation results are examined on two-area power system in the ideally state and in the case of parameter deviation. According to the results, the proposed controllers are resistant to deviation of power system parameters and governor uncertainties.
\end{abstract}

\section{Keywords-load frequency control; LFC; drop characteristics}

\section{INTRODUCTION}

A power system includes multiple power plant units constantly connected to each other while power flux is moving among them. Power systems should be operated in such a way that they remain stable or return to stable condition as soon as possible. If the power system frequency -which is equal to the frequency of production units electrical power output- is deviated, this leads to a difference between the speed of stator and rotor rotating magnetic fields in the air gap of synchronous generators. If this difference is low or quickly eliminated, synchronous generator remains in stable condition but if this difference becomes greater, the rotating magnetic fields will not be stable in the coupled state. Any synchronous generator output power in the production unit will be injected into the power system. Following this, the load of generator will be eliminated. So, rotational speed of rotor shaft will suddenly increase, which is probable to cause damage like cracks in the rotor or even total destruction of the power system stability. So, frequency of different areas and the power flux between them can be considered as fundamental stability factors in a power system. When load increases, the turbine speed will be reduced. As long as governor coordinates input vapor with new load, speed reduction may lead the power system to instability. Load Frequency Control (LFC) problem is a way to restore nominal values of frequency by adding PI or PID controllers as supplementary controller system.

\section{LOAD FREQUENCY CONTROL}

Since real power $(\mathrm{P})$ with frequency $(\mathrm{f})$ and reactive power (Q) with voltage amplitude $(|\mathrm{V}|)$ are associated, by considering the importance of keeping frequency and voltage amplitude at desirable level, control of real and reactive power is very important. As noted, for a power system to perform in favorable state it is necessary for the frequency to remain constant. In order to maintain frequency stability it is necessary to prevent deviation in the outflow of production units. However, since power in a power system is supplied by a large number of generators, it is necessary the extra power requested to be divided appropriately among production units. Main speed control in each production unit is performed by governor. In other words, governor is the primary frequency controller. Higher control process is performed by other controllers added to the system as supplementary controllers. This process is called load frequency control (LFC).

\section{BACKGROUND AND SOLVING METHODS TAKEN FOR LFC PROBLEM}

Several attempts to solve LFC problem have been carried out. The installation of photovoltaic (PV) in [1] and possible uncertainties caused by time delays in [2] can be mentioned. In [3] complex and nonlinear parameters of a decentralized LFC problem have been inspected. In [4] authors designed a differential controller based on fuzzy logic to solve the LFC problem in a restructured environment. In [5] the problem is solved using a method called SOA. In order to solve LFC problem PID controllers based on genetic algorithm are used. In [6] a two-stage controller which prevents disorders from entering the power system is proposed. LFC solving methods are divided into following categories.

\section{A. Classic Controller}

In this method, error signal is based on the integrated control error. In the classical approach, to reach desirable gain margin $\left(\mathrm{K}_{\mathrm{m}}\right)$ and phase margin $\left(\varphi_{m}\right)$ in Bode plot, Nyquist curve is used as reference locus. This controller is simple to implement but according to the results obtained in [7], power systems containing this controller have poor dynamic performance. 


\section{B. Adaptive Controller}

Adaptive controllers have more flexibility than classic controllers. Some examples are adaptive multipart controller system [8], declined adaptive controllers [9] and adaptive with regard to hydro-thermal production units [10].

\section{Robust Controller}

Significant efforts to protect controller system against the uncertainty parameter changing in a power system are [11-13]. In [12] designing a robust controller based on Qparameterization is presented. In [14] by combining robust and adaptive controllers, a new design of a robust adaptive controller is presented to solve LFC problem.

\section{Intelligent Controller}

Classical and non-flexible controller cannot be a proper response agent for the problem of frequency control in power systems with large dimensions. This led to the use of intelligent control methods [15-17]. In [18] authors presented a $H_{\infty}$-based control method to raise the level of performance in controller system. In [19] intelligent hybrid method using a method based on artificial neural network and fuzzy logic is presented.

\section{E. Digital Controller}

In comparison to analog controllers, digital controllers have high accuracy and reliability, are more compact in size, less sensitive to noise and more flexible. The first attempt to implement a comprehensive digital regulator for direct control on power systems is given in [20]. In [21] authors give important results in the field of digital modeling of LFC problem and an indication that determines the impact of carried out control efforts on power system stability.

\section{GENETIC ALGORITHMS}

GAs are one of the algorithms used in order to optimize engineering problems. The purpose of a GA algorithm is to change variable values through generations in order to optimize a objective function. In this method, the specific initial population (as initial generation) for each variable considered can be customized. It is necessary to take a series of implemented attempts so that each generation has better features than its ancestors. Better property is the presence of values that lead the objective function towards the optimal point. Let $\left[\mathrm{x}_{1}, \mathrm{x}_{2}, \ldots, \mathrm{x}_{\mathrm{n}}\right]$ be the parameters of an optimization problem and $\mathrm{F}\left(\mathrm{x}_{1}, \mathrm{x}_{2}, \ldots, \mathrm{x}_{\mathrm{n}}\right)$ their objective function. The objective is to achieve $x_{i}$ values to be determined in such a way that finally $\mathrm{F}\left(\mathrm{x}_{1}, \mathrm{x}_{2}, \ldots, \mathrm{x}_{\mathrm{n}}\right)$ is located very close to its minimum value. At first, for each $x_{i}$ a matrix with dimension $\mathrm{N} \times \mathrm{P}$ is obtained that has $\mathrm{N}$ chromosomes and each of them has $\mathrm{p}$ genes. Using specific criteria, each chromosome will be equated to a continuous numeric value. Then by putting each of these values in the objective function the desirability of a chromosome can be judged. Most successful chromosomes pass to the next generation and some of them are mutated. The steps are repeated until the objective function reaches optimal point or the changes in objective function's values though generations are meaningless. It should be noted that a huge number of calculations has to be done at each stage because all these steps for each $\mathrm{x}_{\mathrm{i}}$ parameter must be carried out in parallel.

\section{LFC MODELING}

In Figure 1 the relation between change of generator output frequency with input and output torques is shown. $T_{e}$ is output electric torque, $\mathrm{T}_{\mathrm{m}}$ is input mechanical torque, $\mathrm{T}_{\mathrm{a}}$ is acceleration torque and $\mathrm{H}$ is the constant of generator inertia [7].

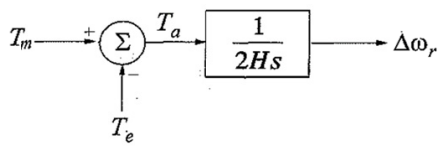

Fig. 1. Conversion function of speed and torques

If statements with high degrees are negligible, (1) is obtained.

$$
\Delta P_{m}-\Delta P_{e}=\Delta T_{m}-\Delta T_{e}
$$

where $\Delta P_{e}$ and $\Delta P_{m}$ are changes of output electrical power and input mechanical power respectively.

\section{A. Load Response forFrequency Deviation}

Load in a power system is a combination of different types of electrical equipment. In general, electrical loads, are divided into two categories, independent of frequency loads (ohm loads, etc.) and frequency-dependent loads (electric motors, etc.). So, load variations equal to change of generator output electric power are expressed as:

$$
\Delta P_{e}=\Delta P_{L}+D \Delta \omega_{r}
$$

In (2), $\Delta P_{L}$ is independent of frequency load changes, $D \Delta \omega_{r}$ is dependent on frequency load changes and $D$ is load damping coefficient. According to the above, the block diagram in Figure 1 is amended as the block diagram in Figure 2 .

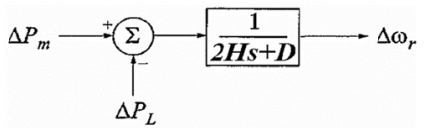

Fig. 2. The function of speed and power by considering the impact of changes in load frequency

\section{B. Isochronous Governor}

An isochronous governor is restoring power system frequency to its nominal value by adjusting turbine valves. It should be noted that this type of governor can operate in one area power systems. If it is used in a multi-area power system, conflicts between production units to bring the system frequency into its planned will emerge and could disrupt the power system stability. To solve this problem, amended governors known as governors by drop characteristics are used.

\section{Governors by Drop Characteristics}

This governor is equipped with a feature that responses to load increase by decreasing the speed. Each production unit has a drop characteristic of its own. Figure 3 shows this type of governor. $\mathrm{R}$ is drop characteristic and $\mathrm{TG}$ is equal to a coefficient of its inverse. 


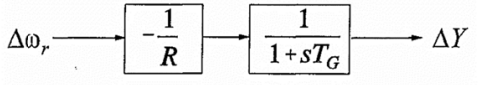

Fig. 3. Block diagram of governors by drop charactristics

The Divided produced power in parallel production units by drop characteristics of each governor is shown in Figure 4.

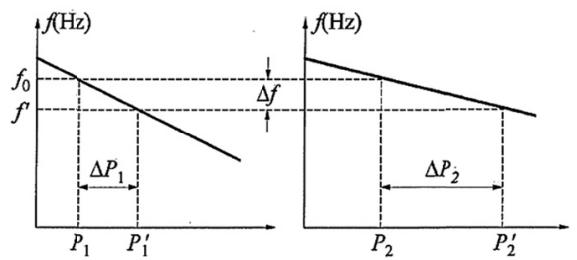

Fig. 4. Dividing power produced in parallel production units by drop characteristics

If $\Delta f$ is the change in frequency, $\Delta P_{L}$ is load changes and $\Delta P_{i}$ is change of output power of production unit $i$. Based on the above we obtain (3)-(5).

$$
\begin{aligned}
& \Delta P_{i}=P_{i}^{\prime}-P_{i}=\frac{\Delta f}{R_{i}} \\
& \frac{\Delta P_{1}}{\Delta P_{2}}=\frac{\Delta R_{2}}{\Delta R_{1}} \\
& \Delta P_{1}+\Delta P_{2}=\Delta P_{L}
\end{aligned}
$$

So, by changing $\Delta P_{L}$ in load the contribution of produced power per unit depending on each drop characteristic is determined. This type of governor in LFC problem leads to a unique frequency $\mathrm{f}^{\prime}$ as a new operating point of the power system. So, unlike isochronous governor in this case, individual generators final speed values are unequal.

\section{Change in Reference Load of ProductionUnits}

According to Figure 4 the power system frequency and the production unit output electric power are related. A way to decrease the oscillation time damping of the frequency is controlling the output power of production units. This type of control is performed by changing the reference load of units as shown in Figure 5.

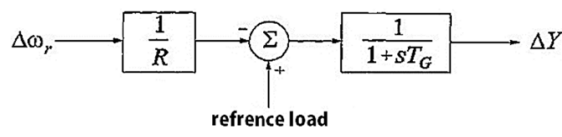

Fig. 5. Governor with reference load control

By changing the reference load, drop characteristic curve of governor shifts up or down. In other words, the output power at any given frequency can be changed by changing the reference load. Figure 6 shows the role of reference load in controlling unit output power and drop characteristic of their governor. In fact, intervening in the stabilization process of a power system is possible by changing the reference load. Therefore, desirable stabilization is done in the shortest time possible and the power system is unstable for less time by the addition of controllers like PI or PID. The overall block diagram of LFC problem for a two-machine system is given in Figure 7.

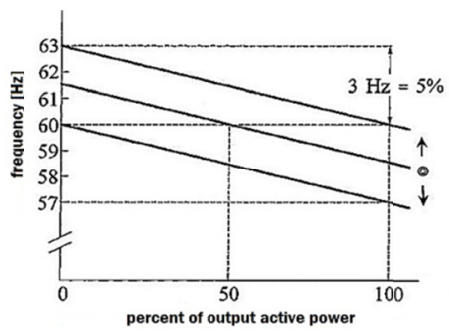

Fig. 6. The effect of changes in setpoint of reference load on governor characteristic drop

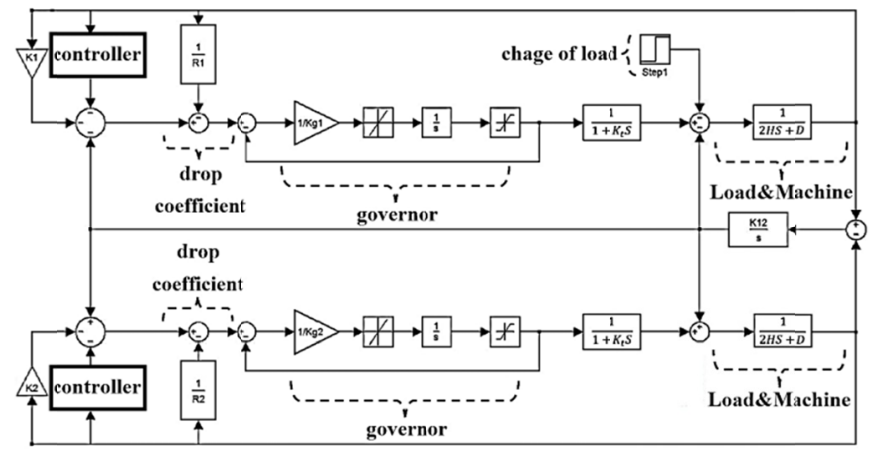

Fig. 7. Overall block diagram of LFC problem for a two-machine system

\section{Simulation}

Based on genetic algorithm PI and PID controllers were designed in MATLAB. Designed controllers were applied to the power system. Simulation results of the enhanced power system's response to an increase of $0.02 \mathrm{pu}$ in load in an area within first 40 seconds after the incident has been investigated in different states. The definition of error signal in load frequency control can be divided in two modes, regardless of the uncertainties (ideal) and considering them.

\section{A. Controller Design in Ideal State}

For the definition of error signal the power system uncertainties are discarded. Equation (6) gives the ideally ITAE error as objective function of LFC problem.

$$
E_{\text {total }}=\left.\int_{0}^{T_{S}} t \cdot\left(\left|\Delta f_{1}\right|+\left|\Delta f_{2}\right|+\left|\Delta p_{12}\right|\right)\right|_{O P_{-} 1.0}
$$

where $\Delta f_{1}$ and $\Delta f_{2}$ are frequency oscillations of areas and $\Delta p_{12}$ is the power flux. The objective function can be implemented in MATLAB by using the block diagram shown in Figure 8. During system operation with the designed controller, it is likely for power system parameters to be deviated. So, it is possible to not achieve optimal damping oscillations. To design PID controller's parameters for the objective function, (6) was used. Obtained optimum values for the designing of the PID controller in ideal state, by using genetic algorithm, are given in Table I. The obtained optimal parameters have been achieved at the 222th step of the GA algorithm. The designed supplementary controller was applied in the power system at $80 \%, 100 \%$ and $120 \%$ of nominal parameter values. Figures 9-11 correspond to the frequency oscillations in zones 1 and 2 and flux oscillations between them. According to Figures 9-11, by designing additional 
controllers, optimal damping for $100 \%$ and $120 \%$ values is obtained. When the power system parameters are at $80 \%$ of their nominal values, the oscillation damping is inappropriate and the power system will become unstable.

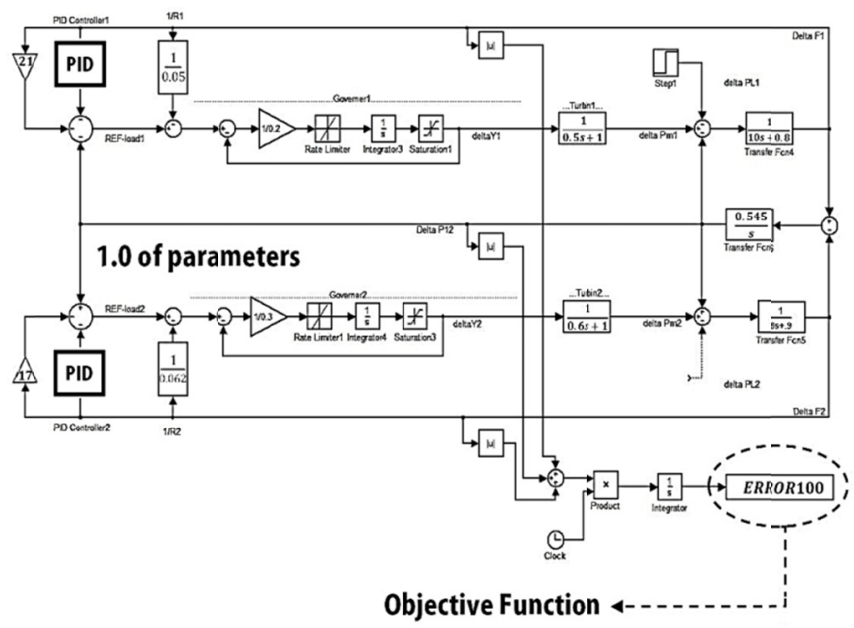

Fig. 8. Block diagram to build ideal LFC objective function
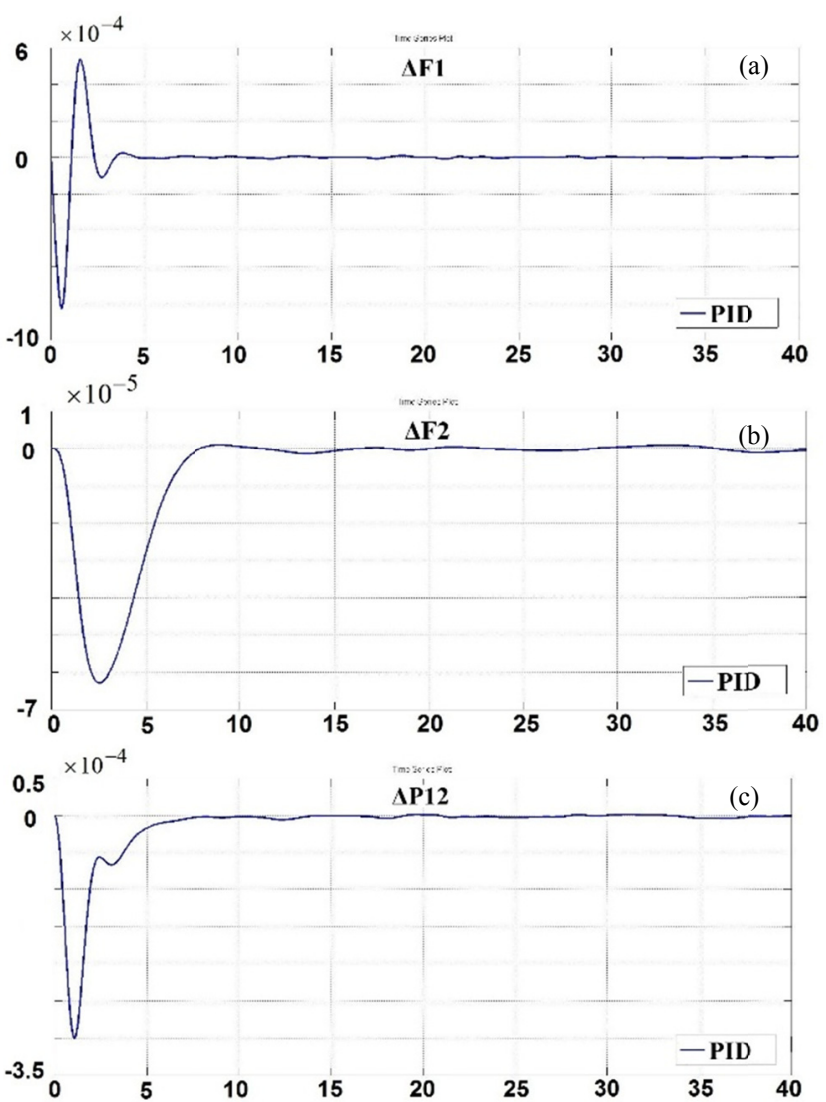

Fig. 9. Applying ideally designed controllers in nominal values: (a) $\Delta \mathrm{f} 1$, (b) $\Delta \mathrm{f} 2$ and (c) Flux oscillations $\Delta \mathrm{p}_{12}$

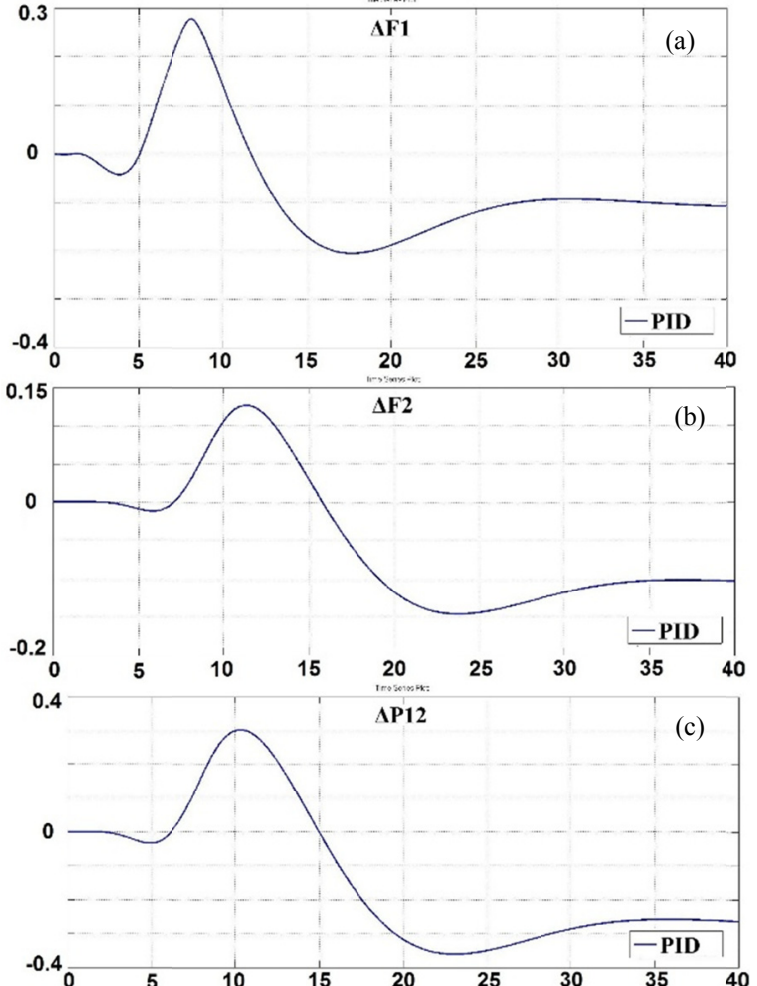

Fig. 10. Applying ideally designed controllers in 0.8 of nominal values: (a) $\Delta \mathrm{f} 1$, (b) $\Delta \mathrm{f} 2$ and (c) $\Delta \mathrm{p}_{12}$
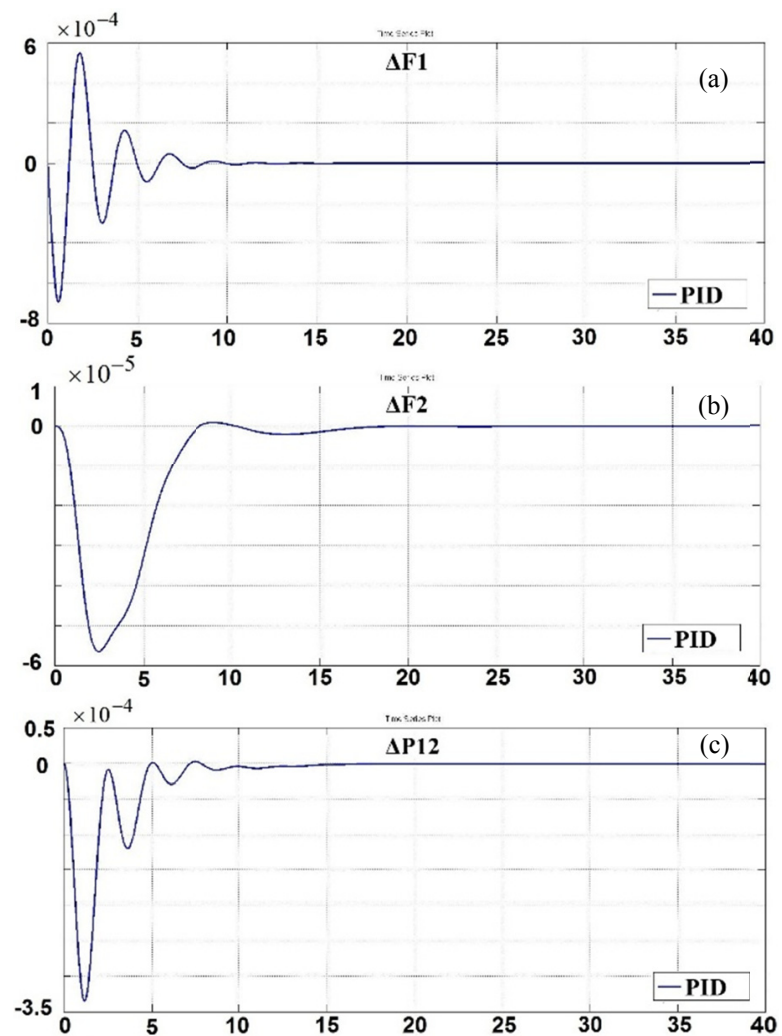

Fig. 11. Applying ideally designed controllers in 1.2 of nominal values: (a) $\Delta \mathrm{f}_{1}$, (b) $\Delta \mathrm{f}_{2}$ and (c) $\Delta \mathrm{p}_{12}$ 
TABLE I. OPTIMAL PID CONTROLLER PARAMETERVALUESIN IDEAL STATE

\begin{tabular}{|c|c|c|}
\hline \multicolumn{3}{|c|}{ PID parameters } \\
\hline \multirow{3}{*}{ Area 1 } & $\mathrm{P}$ & 26.051 \\
\cline { 2 - 3 } & $\mathrm{I}$ & 85.352 \\
\cline { 2 - 3 } & $\mathrm{D}$ & 19.71 \\
\hline \multirow{3}{*}{ Area 2 } & $\mathrm{P}$ & -29.356 \\
\cline { 2 - 3 } & $\mathrm{I}$ & 0.007 \\
\cline { 2 - 3 } & $\mathrm{D}$ & -0.986 \\
\hline
\end{tabular}

\section{B. Controller Design by Considering Uncertainties}

To achieve a robust controller system in addition to nominal mode, it is required to investigate the power system in terms of maximum possible deviation -when parameters are $20 \%$ deviated. In this case, the objective function is:

$$
\begin{aligned}
E_{\text {total }}= & \left.\int_{0}^{T_{S}} t \cdot\left(\left|\Delta f_{1}\right|+\left|\Delta f_{2}\right|+\left|\Delta p_{12}\right|\right)\right|_{O P_{-} 0.8} \\
& +\left.\int_{0}^{T_{S}} t \cdot\left(\left|\Delta f_{1}\right|+\left|\Delta f_{2}\right|+\left|\Delta p_{12}\right|\right)\right|_{O P_{-} 1.0} \\
& +\left.\int_{0}^{T_{S}} t \cdot\left(\left|\Delta f_{1}\right|+\left|\Delta f_{2}\right|+\left|\Delta p_{12}\right|\right)\right|_{O P_{-} 1.2}
\end{aligned}
$$

which can be implemented in MATLAB by using the block diagram shown in Figure 12. Objective function in (7) has been used to design the PI and PID controller parameters. Optimum values obtained for the design of PID and PI controllers in case of uncertainties and by using GA are given in Tables II and III respectively. Optimal values for the design of PID and PI controller has been achieved at 236th and 179th step of the GA algorithm respectively. The results of applying the designed controllers in cases of $100 \%, 80 \%$ and $120 \%$ of nominal values of system parameters are given in Figures 13-15 respectively. According to the results, if the controller design is conducted with regard to uncertainties, optimal damping in frequency oscillations and power flux between areas will be achieved. PID controller acts more favorable than PI in oscillation damping. Since the difference is insignificant, the main role in control process of PID controller is done by the existing PI in it.

TABLE II. OPTIMAL VALUES OF PID CONTROLLER PARAMETERS IN THE CASE OF CONSIDERING UNCERTAINTIES

\begin{tabular}{|c|c|c|}
\hline \multicolumn{3}{|c|}{ PID parameters } \\
\hline \multirow{3}{*}{ Area 1 } & $\mathrm{P}$ & 9.455 \\
\cline { 2 - 3 } & $\mathrm{I}$ & 72.852 \\
\cline { 2 - 3 } Area 2 & $\mathrm{D}$ & 19.363 \\
\cline { 2 - 3 } & $\mathrm{P}$ & -29.667 \\
\cline { 2 - 3 } & $\mathrm{I}$ & 0 \\
\hline \multirow{2}{*}{} & $\mathrm{D}$ & -0.414 \\
\hline
\end{tabular}

TABLE III. OPTIMAL VALUES OF PI CONTROLLER PARAMETERS IN THE CASE OF CONSIDERING UNCERTAINTIES

\begin{tabular}{|c|c|c|}
\hline \multicolumn{3}{|c|}{ PI parameters } \\
\hline \multirow{2}{*}{ Area 1 } & P & -13.586 \\
\cline { 2 - 3 } & I & 11.69 \\
\hline \multirow{2}{*}{ Area 2 } & P & -30.463 \\
\cline { 2 - 3 } & I & 0 \\
\hline
\end{tabular}

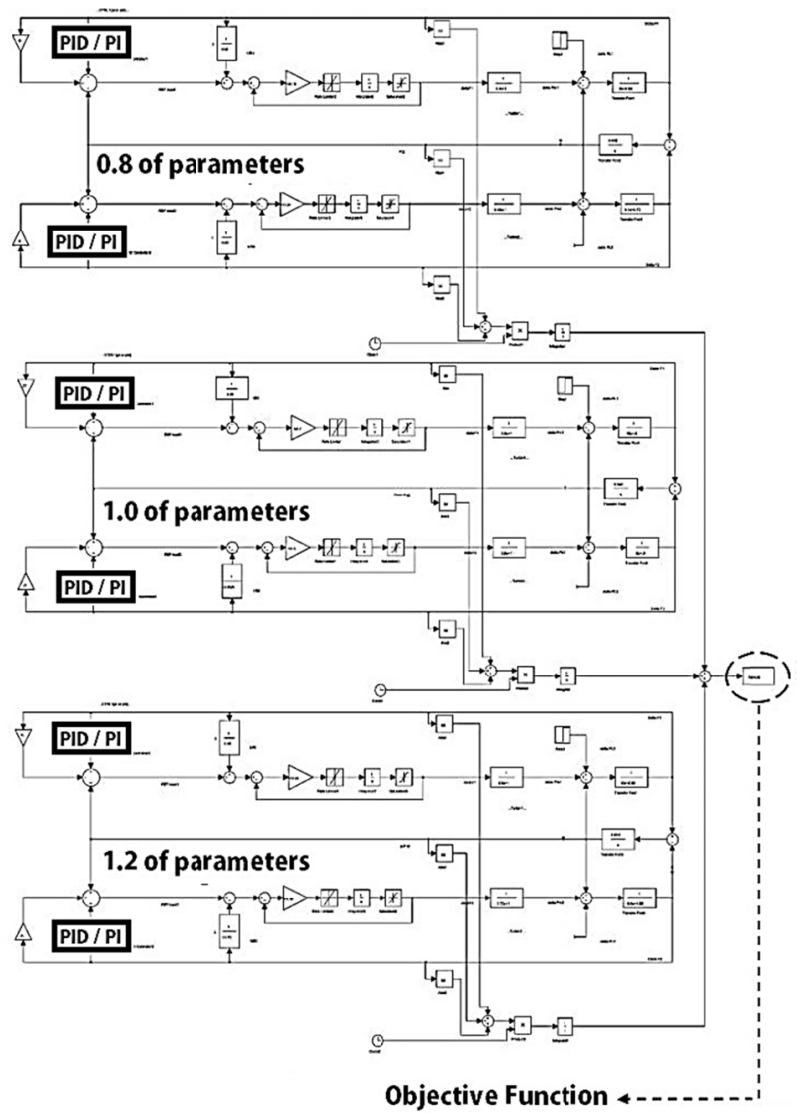

Fig. 12. Block diagram of LFC objective function considering uncertainties
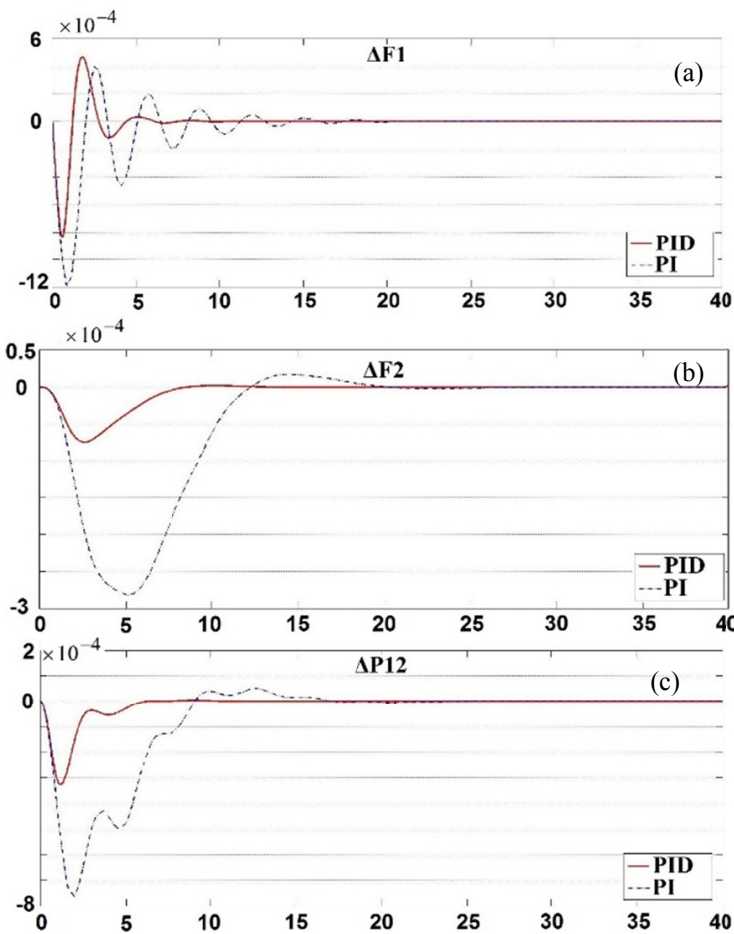

Fig. 13. Applying designed controllers in nominal values in the case of considering uncertainties: (a) $\Delta \mathrm{f} 1$, (b) $\Delta \mathrm{f} 2$ and (c) $\Delta \mathrm{p}_{12}$ 

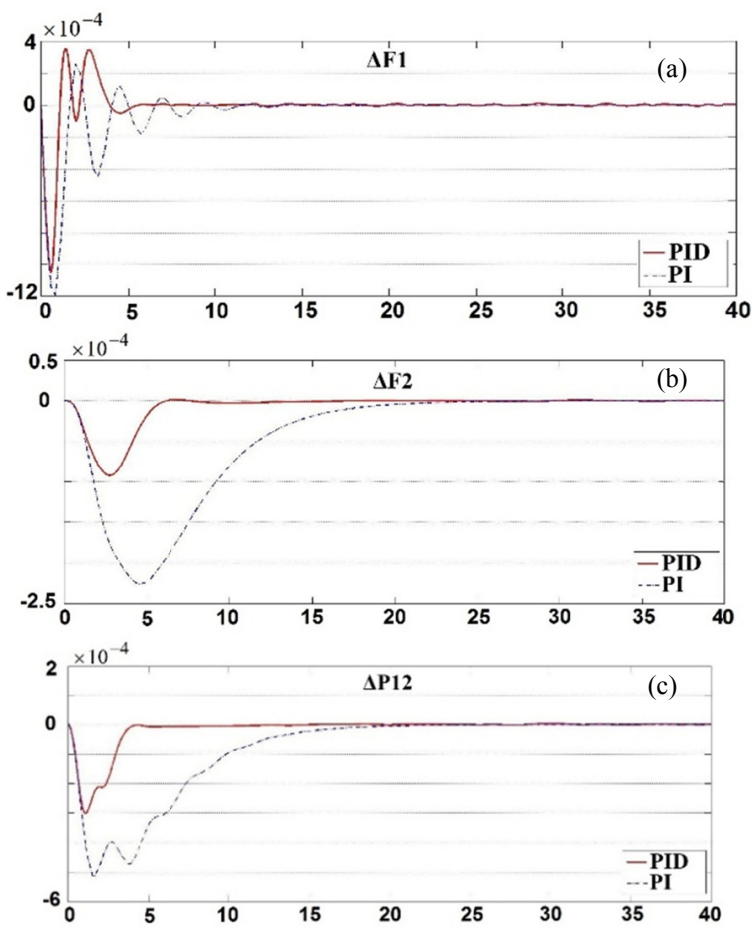

Fig. 14. Applying designed controllers in 0.8 of nominal values in the case of considering uncertainties
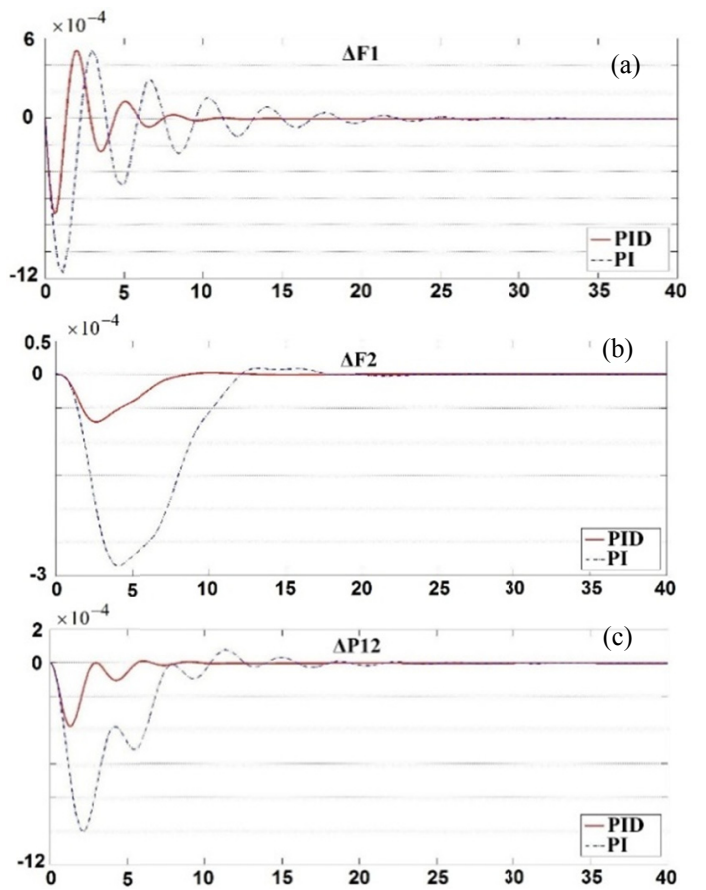

Fig. 15. Applying designed controllers in 1.2 of nominal values in the case of considering uncertainties

\section{Deviation in Operating Point of Governor}

The results of the implementation of ideally designed PI and PID controllers when governor parameters are deviated by $20 \%$ are given in Figure 16.

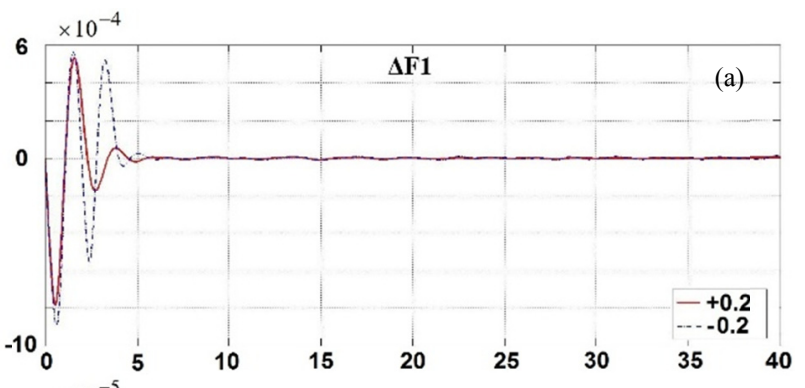

(b)

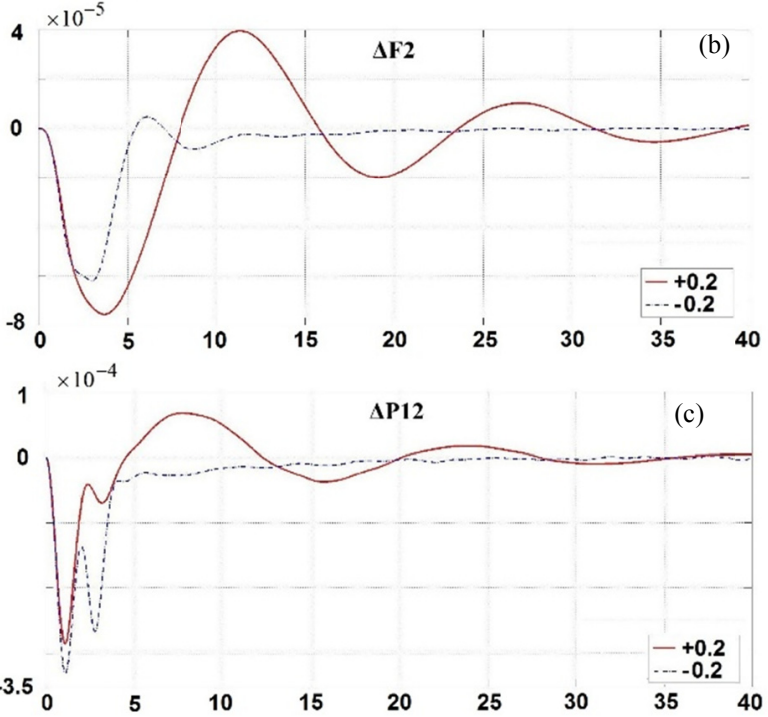

Fig. 16. Implementation of ideally designed controllers with $20 \%$ governor parameters deviation

According to the results in the case of deviations in governor operation point, area frequency oscillations emerged somewhat unfavorable but this event did not cause power system instability.

\section{CONCLUSION}

Frequency stability is one of major necessities in power systems. Controller systems in production units should be implemented to ensure power system stability not only for normal conditions but also after the occurrence of unwanted entries and disorders. Therefore, it is necessary to add controllers like PI or PID with optimized parameters for oscillation damping in the shortest time possible, so that power system is unstable less time. In this paper, GAs was used in order to obtain the controller parameters. However, regardless of uncertainties in the designing of PI and PID controller parameters the designed controller system will be vulnerable in the face of power system parameter deviations. In order to achieve a robust controller system, it is necessary to consider power system parameter deviation among designing supplementary controllers. On the other hand, the PID controller in comparison with the PI controller gives faster results with better oscillation damping. Results show that even in ideal controller design, deviations of governor parameters are not a threat to stability and just cause lower damping. 


\section{REFERENCES}

[1] S. Takayama, R. Matsuhashi, "Development of Model for Load Frequency Control in Power System with Large-scale Integration of Renewable Energy", IEEE Power and Energy Conference, Illinois, USA, pp. 1-8, 2016

[2] C. Peng, J. Zhang, "Delay-Distribution-Dependent Load Frequency Control of Power Systems With Probabilistic Interval Delays", IEEE Transactions on Power Systems, Vol. 31, No. 4, pp. 3309-3317, 2015

[3] T. Fernando, K. Emami, S. Yu, H. Ho-Ching Iu, K. Po Wong, "A Novel Quasi-Decentralized Functional Observer Approach to LFC of Interconnected Power Systems", IEEE Transactions on Power Systems, Vol. 31, No. 4, pp. 3139-3151, 2015

[4] R. Kumar Sahu, G.T. Chandra Sekhar, S. Panda, “ DE optimized fuzzy PID controller with derivative filter for LFC of multisource power system in deregulated environment", Ain Shams Engineering Journal, Vol. 6, No. 9, pp. 511-530, 2015

[5] H. Parvaneh, S. Moradinejad Dizgah, M. Sedighizade, S. Takht Ardeshir, "Load Frequency Control of a Multi-Area Power System by Optimum Designing of Frequency-Based PID Controller Using Seeker Optimization Algorithm", 6th Conference on Thermal Power Plants, Iran, January 19-20, 2016

[6] F. Liu, Y. Li, Y. Cao, J. She, M. Wu, "A Two-Layer Active Disturbance Ejection Controller Design for Load Frequency Control of Interconnected Power System", IEEE Transactions on Power Systems, Vol. 31, No. 16, pp. 3320-3321, 2015

[7] P. Kundur, Power system stability and control, McGraw-Hill, 1994

[8] R. R. Shoults, J. A. Jativa Ibarra, "Multi-area adaptive LFC developed for a comprehensive AGC simulator", IEEE Transactions on Power Systems, Vol. 8, No. 2, pp. 541-547, 1993

[9] C. M. Liaw, "Design of a reduced-order adaptive LFC for an interconnected hydrothermal power system", International Journal of Control, Vol. 60, No. 6, pp. 1051-1063, 1994

[10] A. Rubaai, V. Udo, "Self-tuning LFC: multilevel adaptive approach", IEE Proceedings-Generation, Transmission and Distribution, Vol. 141, No. 4, pp. 285-290, 1994

[11] M. Azzam, "Robust automatic generation control", International Conference on Simulation, York, UK, 30 Sept.-2 Oct. 1998

[12] M. Azzam, Y. S. Mohamed, "Robust controller design for automatic generation control based on Q-parameterization", Energy Conversion and Management, Vol. 43, No. 13, pp. 1663-1673, 2002

[13] M. Karrari, H. Shayeghi, M Abedi, M. B. Menhaj, "Design of H1 controller load frequency control in electrical power systems", Amirkabir Journal of Science \& Technology, Vol. 11, No. 41, pp. 7988,1999

[14] Y. Wang, R. Zhou, C. Wen, "New robust adaptive load frequency control with system parameter uncertainties", IEE ProceedingsGeneration, Transmission and Distribution, Vol. 141, No. 3, pp. 184 189, 1994

[15] B. Franoise, Y. Magid, W. Bernard, "Application of neural networks to load-frequency control in power systems", Neural Networks, Vol. 7, No. 1, pp. 183-194, 1994

[16] L. D. Douglas, T. A. Green, R. A. Kramer, "New approaches to the AGC nonconforming load problem", Power Industry Computer Application Conference, Scottsdale, AZ, USA, May 4-7, 1993

[17] D. K. Chaturvedi, P. S. Satsangi, P. K. Kalra,"Load frequency control: a generalized neural network approach", International Journal of Electrical Power \& Energy Systems, Vol. 21, No. 6, pp. 405-415, 1999

[18] H. Shayeghi, H. A. Shayanfar, "Application of ANN technique for interconnected power system load frequency control", 18th International Power Systems Conference, pp. 33-40, 2003

[19] Y. L. Karnavas, D. P. Papadopoulos, "AGC for autonomous power system using combined intelligent techniques", Electric Power Systems Research, Vol. 62, No. 3, pp. 225-239, 2002

[20] C. W. Ross, T. A. Green, "Dynamic performance evaluation of a computer controlled electric power system", IEEE Transactions on
Power Apparatus and Systems, Vol. PAS-91, No. 3, pp. 1158-1165, 1972

[21] R. Mills, W. Rells, "Automatic generation control. Part I Process modeling", IEEE Transactions on Power Apparatus and Systems, Vol. PAS-92, No. 2, pp. 710-715, 1973 